\title{
EL SISTEMA COMERCIAL ESPAÑOL EN LA ECONOMÍA MUNDIAL (SIGLOS XVII-XVIII). HOMENAJE A JESÚS AGUADO DE LOS REYES
}

\author{
ISABEL LOBATO Y JOSÉ Ma OLIVA (EDS.) \\ Huelva, Publicaciones de la Universidad de Huelva, 2013, 466 páginas \\ ISBN: 978-84-15633-50-1.
}

No es esta la primera vez que el grupo de investigadores encabezados por Carlos Martínez Shaw, José María Oliva y Marina Alfonso presentan una publicación colectiva sobre el sistema comercial español y su inserción en el comercio atlántico y mundial. En esa línea en 2005 ya publicaron El sistema atlántico español, siglos XVII-XIX (C. Martínez Shaw y J. M. Oliva, eds.) y en 2009 España en el comercio marítimo internacional, 1648-1828 (C. Martínez Shaw y M. Alfonso Mola, eds.).

Ahora en El Sistema Comercial Español en la Economia Mundial (siglos XVI-XVIII) se reúnen, todas las direcciones del comercio español entre los siglos XVI y XVIII, dentro del ámbito geográfico impreciso que otorga el concepto Imperio.

Esta propuesta ambiciosa, se aborda desde más de una docena de aportaciones, que si bien no resuelven la idea de conjunto, si aportan como dice I. Lobato en su presentación, una serie de materiales y análisis parciales que nos conducen hacia una mejor “comprensión global de los distintos flujos mercantiles, de sus variados niveles" y en definitiva de un sistema comercial que funciona y se desarrolla a nivel mundial, desde el Atlántico al Pacífico.

H. Pietchsmann dando una visión general, define la forma de organización del comercio español en América desde la perspectiva imperial, considerando el sistema de flotas y galeones como eje vertebrador de dicho imperio. Propone abordar el estudio del comercio americano, no solo desde el aspecto meramente cuantitativo, sino desde la consideración del "aparato simbólico y jurídico que acompañó al sistema de flotas y galeones", de manera que dicho sistema de flotas y galeones se convirtió en una manifestación política imperial, en un entorno geográfico, que en pleno siglo XVIII, se puede calificar como el "Atlántico español”.

Bajo esta construcción imperial se desarrollan diferentes tipos de comercio, desde el de más corta distancia, de cabotaje, entre las costas portuguesas y Cádiz, que detalla en su artículo A. L. López Martínez, o el comercio de Cádiz con el norte de África que analiza de 
E. Martín Corrales; hasta el comercio de larga distancia que se recoge en la contribución de C. Martínez Shaw y M. Alfonso Mola, referida al comercio entre Cádiz y Filipinas. En este último artículo se hace un recorrido por algunos de los proyectos y memoriales de compañías privilegiadas, que en el siglo XVIII proliferaron, y que incidían en un cambio de modelo del comercio con las Filipinas y el extremo oriente, abordando el tráfico directo desde Cádiz.

El tráfico comercial americano se analiza parcialmente desde el virreinato rioplatense. Hernán Asdrúbal Silva explica la incidencia de la guerra de 1796 en los intercambios del Virreinato. La guerra que se inicia en 1796 permitió una ampliación de los intercambios de los puertos principales, Buenos Aires y Montevideo con al menos cien puertos, bien de intermediación o de destino.

El tráfico europeo aparece representado en el capítulo que J.-P. Priotti dedica a la incidencia de las llegadas de plata americana en los puertos bretones y el comercio entre éstos y España. Esas llegadas masivas de plata como afirma Priotti provocarían un cambio en la jerarquía de los puertos bretones, y una reestructuración de los circuitos comerciales, así como nuevas formas de comerciar, primando las ventas al contado sobre las compraventas a crédito, obligando, por tanto, a una fuerte competencia entre grupos de mercaderes, lo que llevaría a una bajada de los costes de transacción.

Junto al tráfico comercial los investigadores que participan en este libro se han detenido de manera especial en las actividades de los agentes comerciales, tanto particulares como colectivos. En este grupo de artículos destacan dos que han sido el producto de las investigaciones llevadas a cabo sobre los fondos diplomáticos del Archivio di Stato di Firenæe. Aunque las fuentes sean similares, la perspectiva de las investigaciones es diferente, mientras que J. M. Melgar utiliza dicha documentación para ofrecer nuevas cifras sobre las remesas de metales llegadas a Cádiz en el siglo XVII, según los enviados florentinos a la corte española; I. Lobato utiliza la documentación del cónsul florentino en Cádiz, Francisco Ginori, para mostrar las actividades de un extranjero en Cádiz a finales del siglo XVII y principios del siglo XVIII, sus desencuentros con las autoridades españoles, sus múltiples negocios, formando parte de numerosas compañías, etc.

Los genoveses son objeto del interés de Catia Brilli, que recoge algunos nombres relevantes de familias de ascendencia genovesa bien integradas en la ciudad de Cádiz, ya en pleno siglo XVIII. La actividad de estos genoveses sigue siendo ante todo comercial, desarrollando un papel importante en el comercio de intermediación entre el mercado mediterráneo y el atlántico y en la Carrera de Indias. 
Siguiendo con el interés por los negocios de los extranjeros J. I. Martínez Ruiz se interesa por la actividad de una compañía dedicada a comerciar entre La Palma y Londres, y J. Aguado de los Reyes reconstruye a través de su investigación la carrera comercial de Tomás Mañara para conseguir un estatus para él o sus hijos en la sociedad sevillana del siglo XVI.

Finalmente, la información comercial se convierte en la conexión entre el tráfico y los agentes comerciales. Es absolutamente necesario para mantener unas redes comerciales eficientes, obtener una información comercial fiable. Esa información puede proceder de contactos personales, de capitanes y maestres que llegan al puerto, por ejemplo, o de correspondientes en otras ciudades; o pueden ser oficiales y periódicas al estilo del Diario del Vigía. Esta publicación recoge el tráfico portuario gaditano desde algunos años finales del siglo XVIII y durante buena parte del siglo XIX. M. Alfonso Mola aporta en este capítulo final interesantes claves metodológicas para su explotación, recordándonos su valor por ejemplo, para reconstruir la flota gaditana del Libre Comercio. Se trata, según M. Alfonso Mola de una fuente útil en sí misma, pero especialmente rentable para el investigador cuando su información se cruza con datos procedentes de otro tipo de fuentes.

En fin, este libro representa una valiosa contribución al análisis del sistema comercial español, en la línea de las investigaciones que viene desarrollando este grupo de investigadores en sus sucesivos proyectos. Estaremos muy pendientes de sus próximas aportaciones.

Guadalupe Carrasco González

Universidad de Cádiz 